\title{
Cardiovascular Pharmacology of Thyrotropin Releasing Hormone
}

\author{
ANNA-LEENA SIRÉN \\ Neurobiology Research Division, Department of Neurology \\ Uniformed Services University of the Health Sciences \\ 4301 Jones Bridge Road, Bethesda, MD 20814-4799
}

Received 19 November 1986

\begin{abstract}
SIRÉN, A.-L. Cardiovascular pharmacology of thyrotropin releasing hormone. PEPTIDES 9: Suppl. 1, 69-73, 1988.Thyrotropin releasing hormone (TRH) and its receptors are present in the cardiovascular nuclei of the brain as well as in the intermediolateral cell column of spinal cord. Anatomical, neurophysiological, functional and pharmacological studies suggest that TRH is a neurotransmitter/neuromodulator in the central nervous system. Administration of TRH to experimental animals or human subjects induces pressor and tachycardic responses and increases plasma levels of catecholamines. These effects are likely to be mediated by a central nervous system activation of the sympathoadrenomedullary system with no involvement of vasopressin or renin-angiotensin system. In the conscious rat, the TRH-induced pressor response is accompanied by an increment in cardiac output and a distinct change in organ blood flow, a hindquarter skeletal muscle vasodilation accompanied bv renal and mesenteric vasoconstriction. The role of TRH in hypertension has not been studied. However, the extremely potent pressor and vasoconstrictor properties of TRH makes this tripeptide a candidate for neurotransmitters/modulators involved in the development and/or maintenance of hypertension. The role of TRH in the therapy of shock is at present controversial. Though preliminary experimental work raised hopes and expectations for therapeutic usage of TRH in shock and trauma, the more recent studies have shown no effect or a detrimental effect for TRH in some experimental shock states.
\end{abstract}

TRH Blood pressure Organ blood flow Sympathetic nerve activity

THYROTROPIN releasing hormone (TRH, I-pyroglutamyl-l-histidyl-l-prolinamide) was the first hypothalamic releasing factor to be isolated, chemically characterized and synthesized [43]. In addition to its neuroendocrine effects (TSH, prolactin, growth hormone release), this tripeptide has central nervous actions which are totally unrelated to its effect on the hypothalamopituitary axis (for review see $[29,38])$. The presence of TRH immunoreactivity and TRH receptors in brain areas related to the cardiorespiratory control, together with the extremely potent pressor and tachycardic actions of exogenously administered TRH suggest that this peptide might have a role in modulating the brain regulation of blood pressure and respiration. This review aims to summarize the studies on TRH in the central nervous system with special emphasis on the cardiovascular pharmacology of this peptide.

\section{TRH SYSTEM IN THE BRAIN}

TRH immunoreactivity is unevenly distributed throughout the central nervous system (see [42,43]). Although the highest local concentrations are found in the hypothalamus (especially in the median eminence, periventricular arcuate, dorsomedial and ventromedial nuclei), more than $70 \%$ of the total CNS TRH is located in extrahypothalamic areas. Outside the hypothalamus high local levels of TRH are found in the lateral nucleus of the septum in the limbic area and in the nucleus of the solitary tract (NTS) in the medulla oblongata; moderate to low levels in preoptic nuclei, midbrain and cor- tex and in the spinal cord [42]. Specific binding sites for TRH in the rat brain were first characterized by Burt and Snyder [6]. Since then, TRH receptors have been found in the brain and spinal cord of many vertebrates including man $[35,36$, $45,49,54]$. Autoradiographic mapping of the receptor sites has revealed a somewhat different distribution of the TRH receptors from that of the peptide TRH. However, the extensive distribution of TRH receptors in the CNS provides an explanation for a variety of central nervous actions ob. served when TRH is administered into the brain [48].

In the rat brain, TRH arises from the post-translational cleavage of a large precursor protein $[31,46]$. Brain synaptosomes are rich in immunoreactive TRH and immunocytochemically TRH has been shown to be present in nerve endings [42]. Moreover, TRH is released in vitro by various stimuli to be retaken up by the rat brain slices in vitro [43].

The findings that TRH is co-localized with substance $P$ and serotonin in some brain nuclei and TRH is able to increase the number of serotonin receptors $[20,48]$ further suggest a neuromodulator role for TRH in the CNS. For more detailed review on the neurochemistry of TRH see the recent reviews of Prasad [43] and Sharif [48].

\section{CARDIOVASCULAR PHARMACOLOGY OF TRH}

TRH induces a strong pressor response in both experimental animals $[3,10,14,27,32,52]$ and in man $[1,4,39,55]$. In animals the TRH-induced hypertensive effect is accom- 
panied with a moderate to strong tachycardia, while in humans it does not seem to affect heart rate. In both anesthetized [32] and conscious [50] rats intracerebroventricularly (ICV) administered TRH is one of the most potent pressor agents known, producing significant increments of mean arterial pressure at subnanomolar doses. A prolonged pressor effect can also be induced by using TRH-analogs such as the CG3703 compound [51] which are highly resistant to TRH metabolizing enzymes [19,38]. Furthermore, the apparent lack of tachyphylaxis to the cardiovascular effects of TRH $[32,50]$ further suggests that this tripeptide might be involved in the pathophysiology of hypertension. However, the potential role of TRH in various experimental hypertensive models must still be elucidated.

\section{Site of Action}

The cardiovascular effects of TRH are likely to be due to an action of the agent on the central nervous system, since the doses needed to elicit rises of mean arterial pressure and heart rate after systemic injections are a thousandfold higher than the doses used ICV or for injections into discrete brain nuclei $[12,14,32,50]$. Moreover, in anesthetized rabbits, transections in the cervical spinal cord abolished the pressor response to ICV administered TRH while spinal transections below $T_{1}$ had no effect on the TRH response [27]. The reversal of leukotriene $\mathrm{D}_{4}$ induced hypotension is also totally abolished in the pithed rat in which the entire CNS and cardiac reflexes are eliminated [15].

A few studies to date have so far tried to localize the pressor and tachycardic effects of TRH in the brain. Feuerstein and coworkers [14] injected nanomolar doses of TRH or its histidyl analogs [16] into the nucleus preopticus medialis (POM) of conscious rats. The magnitude of the increments in mean arterial pressure and heart rate after the POM injections were, however, at the same range as the effect produced by ICV injections of the same doses of TRH $[32,50]$. However, the increase in heart rate was somewhat higher. Microinjections of picomolar doses of TRH into various hypothalamic nuclei in halothane anesthetized rats also elicited slight increases of blood pressure and heart rate without any changes in respiration or body temperature [9]. Immunohistochemical visualization of TRH containing nerve cells and fibers as well as a high density of TRH receptors in the hypothalamus [36, 42,45] further suggest that these brain areas might be important for the cardiovascular actions of TRH. Moreover, endogenous TRH might have a role in the hypothalamic regulation of the cardiovascular system. In contrast to these findings, it was recently reported that the pressor response to TRH can be elicited also with injections into the fourth ventricle [41]. Moreover, occlusion of the cerebral aqueduct attenuated the increment of blood pressure produced by ICV administered TRH, while the tachycardia induced by TRH was unaffected by this procedure [41]. These findings suggest that the pressor response to TRH can, at least in part, be due to an activation of brain areas within the reach of the fourth ventricle. The nucleus of the solitary tract has been shown to have a high content of TRH immunoreactivity [42] and also TRH receptors [36]. However, microinjections of nanomolar doses of TRH into the NTS of the pentobarbitone anesthetized rat elicited, instead of a pressor effect, a moderate depressor response on blood pressure which was accompanied by a slight tachycardia [14]. The NTS has been indicated to be a sensitive brain site for the respiratory stimulant action (tachypnea, increase in ventilatory volume) in the rat $[8,22]$.
Hemodynamic Mechanism Involved in the Cardiovascular Actions of TRH

Although the pressor and tachycardic effects of TRH have been repeatedly documented (see above), little is known for the hemodynamic and regional blood flow changes after TRH administration. By using the thermodilution technique we found that the pressor and tachycardic effects of both ICV and systemically administered TRH were accompanied by a simultaneous increase in cardiac output. while TRH had no effect on total peripheral resistance (Sirén et al., manuscript in preparation). The same pattern of hemodynamic changes was observed also after systemic injection of a potent TRH analog, CG3703 [19], in conscious rats [51]. In man, TRH injected intravenously seems to produce opposite changes in gross hemodynamic variables and the pressor response in humans is more likely to be due to an increase in resistance than to an increment of cardiac output [55]. By using the ultrasound directional pulsed Doppler method we have also shown [50] that ICV administration of low doses $(0.8-80 \mathrm{nmol} / \mathrm{kg})$ of TRH produced a distinct pattern of regional blood flow changes in the conscious rat: the blood flow to skeletal muscles significantly increased and vascular resistance decreased after TRH injections, with opposite changes in the renal (and to a lesser degree in the mesenteric) blood flow and vascular resistance. The differential pattern of blood flow changes in these vascular beds might explain the lack of effect of TRH on total peripheral resistance. These findings also underline the importance in studying the effect of TRH (and other peptides) on regional blood flow and vascular resistance; the potent vasoconstrictor effect of TRH on the renal vasculature might not only play a role in the regulation of renal hemodynamics but also indirectly in the control of systemic blood pressure.

\section{The Role of the Autonomic Nervous Sustem}

The cardiovascular effects of TRH have been related to an activation of sympathetic outflow, since these changes are accompanied by increases in plasma catecholamines in both animals [5,14] and man [39]. Although measuring plasma catecholamines might not be a good index for the sympathetic nerve activity, these suggestions are further supported by the findings that the pressor effect of ICV administered TRH in rat endotoxic shock is abolished by adrenal demedullation [26]. In conscious adrenal demedullated rats, the tachycardia elicited by TRH injections into the POM was also inhibited and the pressor response partly attenuated by bretylium treatment [14]. Studies in progress in our laboratory have revealed that the increments of blood pressure, heart rate and cardiac index induced by TRH are partly attenuated in adrenal demedullated rats, and are not significantly effected by further treatment with bretylium. The renal vasoconstrictor response to TRH, on the other hand, is reduced to $50 \%$ in adrenal demedullated animals and the vasodilation in skeletal muscle almost totally inhibited by bretylium in these rats. As compared to the other known vasoactive substances such as epinephrine, norepinephrine, angiotensin, vasopressin or platelet activating factor $([11,13$, 51], unpublished findings of our laboratory), the pattern of the changes in blood flow in skeletal muscle, mesenteric and renal vascular beds by TRH mostly resembled that induced by norepinephrine while all the other above mentioned agents induced totally different changes in blood flow as that produced by TRH. Furthermore, direct resolving of renal sympathetic nerve activity in anesthetized rats revealed a 


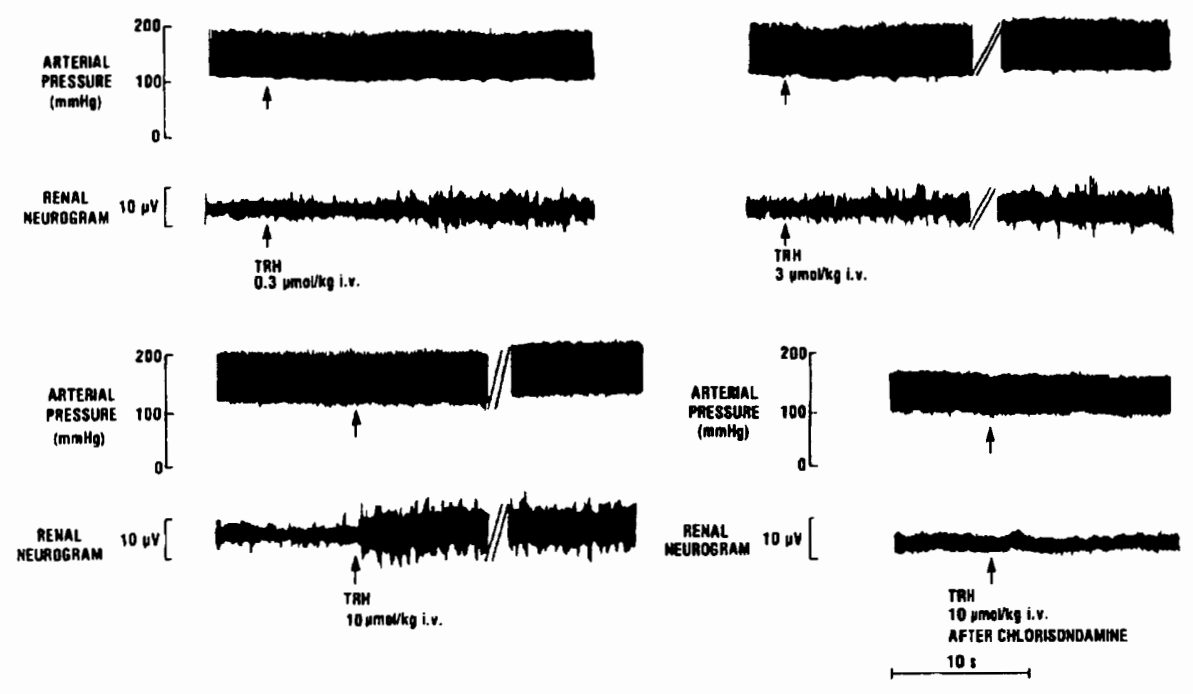

FIG. 1. A representable chart recording of arterial pressure (AP) and renal sympathetic nerve activity (RSNA) in the anesthetized rat after intravenous injections of THR $(0.3-10 \mu \mathrm{mol} / \mathrm{kg})$. Chlorisondamine $(5 \mathrm{mg} / \mathrm{kg})$ was administered intravenously $20 \mathrm{~min}$ before injection of TRH at the highest dose (10 $\mu \mathrm{mol} / \mathrm{kg}$ ) was repeated.

profound activation of nerve firing by TRH even at doses which did not affect the arterial pressure (Fig. 1). Both the hemodynamic and neural effects of TRH were abolished by the ganglion blocker chlorisondamine (Fig. 1). These data taken together suggest that the cardiovascular effects of TRH, at least in part, involve an activation of the sympathoadrenomedullary axis. However, any pharmacological intervention to block the sympathetic or parasympathetic pathways (hexamethonium, reserpine, phentolamine, propranolol, atropine) were not effective in inhibiting the increases in blood pressure and heart rate produced by TRH ICV in the anesthetized rabbit $[27,28]$. Thus, the involvement of sympathetic nerves and adrenal medulla in the cardiovascular actions of TRH is at present clearly controversial. Although an incomplete blockade of adrenergic nerves and/or receptors by sympathetic blocking agents might explain the lack of inhibition of TRH effects in the studies cited above, a nonadrenergic component of action may also be proposed. This view is further supported by the recent clinical findings by Zaloga and coworkers [55] that the pressor response to TRH in humans was not accompanied by any increments of plasma catecholamines. The importance of vasopressin and renin-angiotensin system in the TRHinduced cardiovascular changes is discussed in the next chapter. Briefly, neither of these systems seem to be involved. It is therefore possible that neurotransmitters other than norepinephrine which are released by sympathetic activation contribute to the cardiovascular responses to TRH. Possible candidates for such neurotransmitters might include neuropeptide Y (NPY) or opioid peptides which are colocalized and coreleased from sympathetic nerve endings and adrenal medulla with norepinephrine $[18,40]$. Systemic administration of NPY to rats results in vasoconstrictor and pressor responses similar to TRH [40], while the effects of various opioid peptides are more complex [18]. However, the importance of these mediators in the cardiovascular action of TRH must still be elucidated. Furthermore, direct recording of sympathetic nerve traffic to various organs following TRH administration would further clarify the role of the sympathoadrenomedullary system in the vasoconstrictor/vasodilator actions of TRH.

\section{Other Possible Mediators of the TRH Effect}

Plasma vasopressin levels have been reported to increase after systemic or central administration of TRH in rabbits $[28,53]$, while in dogs TRH does not have any effect on plasma vasopressin [30]. However, the increment in plasma vasopressin seems to be unrelated to its cardiovascular actions, since hexamethonium blocked the effect of TRH on vasopressin but had no influence to its concomitant pressor response [28]. Moreover, repeated administrations of vasopressin to anesthetized rabbits (to induce tachyphylaxis) had no effect on the TRH-induced hypertensive response [28]. Studies in progress in our laboratory have shown that in the conscious rat systemic administration of a high dose of TRH $(2 \mathrm{mg} / \mathrm{kg})$ induced a statistically significant rise in plasma vasopressin, but the magnitude of this increase was below the levels at which vasopressin can induce changes in blood pressure [7]. Pretreatment of urethane-anesthetized rats with a vasopressin antagonist failed to block the cardiovascular actions of ICV administered TRH [37]. The involvement of the other pressor system, the renin-angiotensin system, in the hypertensive effect of TRH seems also likely, since TRH has no effect on plasma renin activity in either the conscious rat (own unpublished observations) or in man [39].

\section{TRH in Shock}

Holaday and coworkers $[24,25]$ were the first to suggest that TRH might have a beneficial effect in cardiovascular shock. They found that a systemic injection of a high dose of TRH $(2 \mathrm{mg} / \mathrm{kg})$ reversed the hypotension in rat hemorrhagic [24] and endotoxic shock [25]. Studies in our laboratory have shown that TRH, administered both systemically and di- 
rectly into the brain ventricles, reversed also the hypotension induced by leukotriene $\mathrm{D}_{4}$, platelet activating factor, soybean lipoxygenase or antigen induced anaphylaxis in the conscious guinea pig $[17,33,34]$. In contrast to its well documented pressor response in cardiovascular shock, the beneficial effect of TRH in various shock states seems to be controversial. Holaday et al. [25] reported increased shortterm survival ( 2 hours after the shock) by TRH in endotoxic shock but had no data on the survival in rat hemorrhagic shock. Some preliminary studies on cynomulgus monkeys $[21,44]$, on the other hand, suggest a beneficial effect of TRH on survival in hemorrhagic shock but not in the endotoxic shock. In mice anaphylactic shock TRH significantly reduced mortality which was probably mediated by a central nervous stimulation of the sympathetic outflow [2]. Our recent results [51] clearly showed that TRH or its long-acting analogue CG3703 (see above) increased mortality in conscious rats exposed to hemorrhage. In addition to the reduced survival, we also found that the pressor effect induced by CG3703 in rat hypovolemic hypotension was due to a sharp increase in the total peripheral resistance, while the cardiac output tended to be reduced by the treatment. Moreover, the regional blood flow in skeletal muscle, mesenteric and renal vascular beds was significantly impaired by the treatment. These results may thus provide explanation for the lack of beneficial effect of TRH; reduced blood flow to vital organs together with the reduction of cardiac output. The lack of any beneficial effect of TRH on either cardiovascular parameters or survival in cat or rabbit hemorrhagic shock or in rat traumatic shock was recently confirmed by others $[23,47]$.

Thus, the beneficial effect of TRH in shock seems to be dependent on the shock model as well as the species studied. TRH and its stable analogs may prove to be beneficial in anaphylactic shock whereas in hypovolemic shock, TRH exacerbates the shock and causes a sustained reduction of blood flow in vital organs.

\section{SUMMARY}

TRH immunoreactivity and highly specific binding sites for TRH are found in neuronal cell bodies and fibers throughout the vertebrate central nervous system. The neuromodulator role for TRH is further suggested by the facts that in the brain this tripeptide arises from a large precursor protein and has its own releasing, uptake and degradation mechanisms. Administration of TRH to animals or man induces a potent pressor response and increases plasma catecholamine levels probably mainly by a central nervous activation of sympathoadrenomedullary axis. In the rat, the TRH-induced pressor response is accompanied by increases in heart rate and cardiac output and skeletal muscle blood flow, while in renal and mesenteric vasculature it produces vasoconstriction. The cardiovascular actions of TRH seem not to involve other known pressor systems such as the renin-angiotensin system or vasopressin release. The role of TRH in different hypertension models has not been studied. However, the extremely potent pressor effect of this peptide makes TRH a candidate for neurotransmitters or modulators involved in the development and/or maintenance of hypertension.

The role of TRH in the therapy of a variety of shock states and trauma is at present controversial. Although preliminary experimental work raised hopes and expectations for therapeutic usage of TRH in shock and trauma, the more recent studies have shown no effect or a detrimental effect for TRH in some experimental shock states.

\section{ACKNOWLEDGEMENTS}

This work is supported in part by USUHS protocol No. RO9232. The opinions or assertions contained herein are the private ones of the authors and are not to be construed as official or reflecting the view of the Department of Defense of the Uniformed Services University of the Health Sciences. The author wishes to thank Ms. Wanda Patterson and Laura Garza for their help in the preparation of this manuscript.

\section{REFERENCES}

1. Abplanalp, V. H. A. Hamodynamische effekte nach intravenoser applikation von thyrotropin releasing factor. Arzneimittelforsch 22: 271-277, 1976.

2. Amir, S., M. Harel and A. Schachar. Thyrotropin releasing hormone (TRH) improves survival in anaphylactic shock: a central effect mediated by the sympatho-adrenomedullary $\beta$-adrenoceptive system. Brain Res 298: 219-224, 1984.

3. Beale, J. S., R. P. White and S.-P. Huang. EEG and blood pressure effects of TRH in rabbits. Neuropharmacology 16: 499-506, 1977

4. Borowski, G. D., C. D. Garofano, L. I. Rose and R. A. Levy. Blood pressure response to thyrotropin-releasing hormone in euthyroid subjects. J Clin Endocrinol Metab 58: 197-200, 1984.

5. Brown, M. R. Thyrotropin releasing factor: a putative CNS regulator of the autonomic nervous system. Life Sci 28: 1789 1795, 1981.

6. Burt, D. R, and S. H. Snyder. Thyrotropin releasing hormone (TRH): apparent receptor binding in rat brain membranes. Brain Res 93: 309-328, 1975.

7. Cowley, A. W., Jr., E. W. Quillen, Jr. and M. M. Skelton. Role of vasopressin in cardiovascular regulation. Fed Proc 42: 3170$3176,1983$.

8. Dekin, M. S., G. B. Richerson and P. A. Getting. Thyrotropin releasing hormone induces rhythmic bursting in neurons of the nucleus tractus solitarius. Science 229: 67-69, 1985.
9. Diz, D. I. and D. M. Jacobowitz. Cardiovascular effects produced by injections of thyrotropin-releasing hormone in specific preoptic and hypothalamic nuclei in the rat. Peptides 5: 801-808, 1984.

10. Eriksson, L. and A. Gordin. Cardiovascular and behavioral changes after ICV infusion of TRH in the conscious goat. Pharmacol Biochem Behav 14: 901-905, 1981.

11. Faber, J. E., K. W. Barron, A. C. Bonham, R. Lappe, E. E. Muirhead and M. J. Brody. Regional hemodynamic effects of antihypertensive neuromedullary lipids in conscious rats. Hypertension 6: 494-502, 1984.

12. Faden, A. I., T. P. Jacobs and J. W. Holaday. Thyrotropin releasing hormone improves neurologic recovery after spinal trauma in cats. N Engl J Med 305: 1063-1067, 1981.

13. Feuerstein, G. and R. E. Goldstein. Effect of PAF on the cardiovascular system. In: Platelet Activating Factor, edited by $S$. Snyder. In press, 1986.

14. Feuerstein, G., A. H. Hassen and A. I. Faden. TRH: cardiovascular and sympathetic modulation in brain nuclei of the rat. Peptides 4: 617-620, 1983.

15. Feuerstein, G., Z. Zukowska-Grojec, M. Bayorh, I. J. Kopin and $A$. I. Faden. Leukotriene $D_{4}$-induced hypotension is reversed by thyrotropin releasing hormone. Prostaglandins 26: $711-724,1983$. 
16. Feuerstein, G., D. Lozovosky, L. A. Cohen, V. M. Labroo, K. L. Kirk, I. J. Kopin and A. I. Faden. Differential effect of fluorinated analogs of TRH on the cardiovascular system and prolactin release. Neuropeptides 4: 303-310, 1984.

17. Feuerstein, G., W. E. Lux, Jr., D. Ezra, E. C. Hayes, F. Snyder and A. I. Faden. Thyrotropin releasing hormone blocks the hypotensive effects of platelet activating factor in the unanesthetized guinea pig. I Cardiovasc Pharmacol 7: 335-340, 1985.

18. Feuerstein, G. and A.-L. Siren. Opioid system in cardiac and vascular regulation of normal and hypertensive states. Circula. tion, in press, 1986 .

19. Friederichs, E., E. Schwertner, S. Herrling, W.-A. Gunzler, F. Otting and L. Flohe. Activity of thyroliberin analogs with a modified pyroglutamyl residue on the central nervous system. In: Structure and Activity of Natural Peptides. Berlin: Walter de Gruyter, 1981, pp. 461-481.

20. Funatsu, K., S. Teshima and K. Inanaga. Thyrotropin releasing hormone increases 5-hydroxytryptamine receptors in the limbic brain of the rat. Peptides 6: 563-566, 1985.

21. Gurll, N. J., D. G. Reynolds, J. Holaday and E. Ganes. Improved cardiovascular function and survival using thyrotropin releasing hormone (TRH) in primate hemorrhagic shock. Physiologist 25: 342, 1982.

22. Hedner, J., T. Hedner, J. Jonason and D. Lundberg. Central respiratory stimulant effect by thyrotropin in releasing hormone in the rat. Neurosci Lett 25: 317-320, 1981.

23. Hock, C. E. and A. M. Lefer. Lack of effect of thyrotropin releasing hormone (TRH) in circulatory shock. Peptides 6 : 547-553, 1985.

24. Holaday, J. W., R. J. D'Amato and A. I. Faden. Thyrotropin releasing hormone improves cardiovascular function in experimental endotoxic and hemorrhagic shock. Science 213: 216-218, 1981.

25. Holaday, J. W., B. A. Ruvio and A. I. Faden. Thyrotropin releasing hormone improves blood pressure and survival in endotoxic shock. Eur J Pharmacol 74: 101-105, 1981.

26. Holaday, J. W. and A. I. Faden. Thyrotropin releasing hormone: autonomic effects upon cardiorespiratory function in endotoxic shock. Regul Pept 7: 111-125, 1983.

27. Horita, A. and M. A. Carino. Centrally administered TRH produces a vasopressin response in rabbits. Proc West Phar. macol Soc 20: 303-304, 1977.

28. Horita, A., M. A. Carino and R. E. Weitzman. Role of catecholamine and vasopressin release in the TRH-induced vasopressin response. In: Catecholamines: Basic and Clinical Frontiers, Vol 2, edited by E. Usdin, I. J. Kopin and J. Barchas. New York: J. Barches, 1979, pp. 1140-1142.

29. Horita, A., P. W. Kalivas and S. M. Simasko. Thyrotropin releasing hormone (TRH): possible physiological functions not related to the neuroendocrine system. Rev Pure Appl Pharmacol Sci 4: 111-137, 1983.

30. Huffman, L. J., G. T. Campbell and J. P. Gilmore. Renal function and pituitary hormone release during cerebral osmostimulation and TRH in dogs. Peptides 4: 843-847, 1983.

31. Jackson, I. M. D. and P. Wu. Immunohistochemical localization in the rat brain of the precursor for thyrotropin releasing hormone. Science 229: 1097-1099, 1985.

32. Koivusalo, F., I. Paakkari, J. Leppaluoto and H. Karppanen. The effect of centrally administered TRH on blood pressure, heart rate and ventilation in rat. Acta Physiol Scand 106: 83-86, 1979.

33. Lux, W. E., Jr., G. Feuerstein and A. I. Faden. Alteration of leukotriene $\mathrm{D}_{4}$ hypotension by thyrotropin releasing hormone. Nature 302: 822-824, 1983.

34. Lux, W. E., Jr., G. Feuerstein and A. I. Faden. Thyrotropin releasing hormone reverses the hypotension and bradycardia produced by leukotriene $D_{4}$ in unanesthetized guinea pigs. Prostaglandins Leukotrienes Med 10: 301-307, 1983.
35. Manaker, S., A. Winokur, C. H. Rhodes and T. C. Rainbow, Autoradiographic localization of thyrotropin releasing hormone (TRH) receptors in human spinal cord. Neurology 35: 328-332, 1985.

36. Manaker, S., A. Winokur, W. H. Rostene and T. C. Rainbow. Autoradiographic localization of thyrotropin releasing hormone receptors in the rat central nervous system. J Neurosci 5: 167174, 1985.

37. Mattila, J. and R. D. Bunag. Sympathetic renal pressor responses to centrally infused thyrotropin releasing hormone (TRH) in rats. Pharmacologist 28: 216, 1985.

38. Metcalf, G. Reguatory peptides as a source of new drugs-the clinical prospects for analogues of TRH which are resistant to metabolic degradation. Brain Res Rev 4: 389-408, 1982.

39. Morley, J. E., M. L. Tuck, D. M. Mayes, S. Rosenblatt and J. M. Hershman. Thyrotropin releasing hormone increases plasma norepinephrine in man. Horm Res 14: 18-23, 1981.

40. O'Donahue, T. Z., B. M. Chronwall, R. M. Pruss, E. Mezey, J. Z. Kiss, L. E. Eiden, V. J. Massari, R. D. Tessel, V. M. Pickel, D. A. DiMaggio, A. J. Hotchkiss, W. R. Crowley and Z. Zukowska-Grojec. Neuropeptide $Y$ and peptide YY neuronal and endocrine systems. Peptides 6: 755-768, 1985.

41. Paakkari, I., M.-L. Nurminen and A.-L. Sirén. Cardioventilatory effects of TRH in anesthetized rats: role of the brainstem. Eur J Pharmacol 122: 131-134, 1986.

42. Palkovits, M. Distribution of neuropeptides in the central nervous system: a review of biochemical mapping studies. Prog Neurobiol 23: 151-189, 1984.

43. Prasad, C. Thyrotropine releasing hormone. In: Handbook of Neurochemistry, edited by A. Lajtha. New York: Plenum Publishing Corporation, 1985, pp. 175-200.

44. Reynolds, D. C., N. J. Gurll, J. Holaday and E. Ganes. Thyrotropin releasing hormone (TRH) in primate endotoxic shock. Physiologist 25: 309, 1982.

45. Rostene, W. H., J.-L. Morgat, M. Dussaillant, T. C. Rainbow, A. Sarrieau, M. Vial and G. Rossekin. In vitro biochemical characterization and autoradiographic distribution of ${ }^{3} \mathrm{H}-$ thyrotropin releasing hormone binding sites in rat brain sections. Neurvendocrinology 39: 81-86, 1984.

46. Rupnow, J. H., P. M. Hinkle and J. E. Dixon. A macromolecule which gives rise to thyrotropin releasing hormone. Biochem Biophys Res Commun 89: 721-728, 1979.

47. Sampson, J. A., B. L. Blass, J. W. Harmon and J. Holaday. Investigation of the hypertensive effect of TRH in rabbit hemorrhagic shock. Circ Shock 16: 62, 1985.

48. Sharif, N. A. Diverse roles of thyrotropin releasing hormone in brain, pituitary and spinal function. Trends Pharmacol Sci 6: $119-122,1985$.

49. Sharif, N. A. and D. R. Burt. Visualization and identification of TRH receptors in rodent brain by autoradiography and radioreceptor assays: focus on amygdala, $N$. accumbens, septum and cortex. Neurochem Int 7: 525-532, 1985.

50. Sirén, A.-L. and G. Feuerstein. Effect of thyrotropin releasing hormone on blood pressure and peripheral blood flow in conscious rats. Fed Proc 44: 721, 1985.

51. Siren, A.-L., E. Powell and G. Feuerstein. Thyrotropin releasing hormone in hemorrhagic shock: effects on cardiac output and regional blood flow. Circ Shock 16: 75, 1985.

52. Tsay, B. L. and M. T. Lin. Effects of intracerebroventricular administration of thyrotropin releasing hormone on cardiovascular function in the rat. Neuroendocrinology 35: 173-177, 1982.

53. Weitzman, R. E., H. M. Firemark, T. H. Glatz and D. A Fisher. Thyrotropin releasing hormone stimulates release of arginine vasopressin and oxytocin in vivo. Endocrinology 104: 904-907, 1979.

54. Winokur, A., S. Manaker, A. Eichen, C. H. Rhodes and T. C. Rainbow. Autoradiographic localization of thyrotropin releasing hormone (TRH) receptors in human brain. Soc Neurosci Abstr 2: 901,1985

55. Zaloga, G. P., B. Chernow, R. Zajtchuk, R. Chin, T. G. Rainey and C. R. Lake. Diagnostic dosages of protirelin (TRH) elevate BP by noncatecholamine mechanisms. Arch Intern Med 144: 1149-1152, 1984. 